\title{
Factors Impacting Small Business Owners Decision Regarding Changes in Customer Base and Geographic Scope
}

\author{
Al Hawkins, (E-Mail: alfred.hawkins@rockhurst.edu),Rockhurst University \\ Richard E. Hunt, Deceased, Rockhurst University \\ David Adams, Maywood College
}

\begin{abstract}
T-test comparisons of midwestern small business owners indicate that the decisions to change customer base or geographic scope of marketing are primarily influenced by the owner's tendency to monitor his/her relevant marketing environment, the owner's willingness to seek outside marketing assistance during the early stages of the business and by whether they initially were significantly higher or lower in their starting base than owners who did not change. Also, owners who changed their customer base and/or geographic scope were significantly more likely to change the degree of emphasis they gave to their original customers and geographic scope; however, this was not a zero-sum game for those who expanded.
\end{abstract}

\section{Introduction}

7 he decision to change the customer base by adding new customer segments and/or geographic scope of a business' marketing efforts is critical to the success of the business. This is especially true for the small business, where the typical lack of resources allows little room for miscalculation. Given this, it is worth considering what factors are likely to be associated with such decisions. Since the small business is disproportionately likely to be driven by the deci-

Readers with comments or questions are encouraged to contact the author via e-mail. sions of the owner, are there personal or experiential characteristics of the owner that would be associated with variability of such decisions? Similarly, the results of actions taken during the start-up phase of the business, as well as subsequent outcomes, could also be possible explanatory variables.

This research focuses on attempting to determine if such significant factors exist and whether they vary depending on the type of decision, i.e. are the same factors associated with changes in customer base as with changes in geographic scope. Also, would we 
find a different profile for cases where expansion is occurring versus contraction?

\section{Literature Review}

Cook (1994) suggests that effective planning is a key to small business success. He recommends that the small business owner base the company's sales plan on a through analysis of its target market. Thus, environmental monitoring is a critical owner/manager behavior. Yet, Snyder (1987) points out that individuals vary significantly in terms of their predisposition towards monitoring their relevant external environment. Hunt and Adams (1996) found that business owners who were high monitors of their relevant business environments were able to guide their businesses to significantly higher levels of yearly improvement than were owners who were low monitors.

Pelham and Clayson (1988) found that even though marketing analysis is viewed as critical to the future of the venture by a sample of business owners/managers, they indicated that it was the second lowest activity in terms of their time allocation. Brush (1992) found that new ventures usually engaged in non-systematic, informal methods of gathering marketing information, while Mohan-Neil (1995) concluded that new ventures gathered significantly less marketplace information that did older and larger firms.

While many small businesses use a "shot-gun" approach to seeking customers, this flies in the facing of conventional wisdom, e.g. the 20/80 rule, that suggests most of your profitable business will come from a limited part of the potential customer population. Berry and Britney (1996) suggested that the key to growth for small business banking is to segment the market to determine those customers most valuable for retention. Sheldon (1994) points out that failure to update the small business' plan regarding which customers to pursue is a common cause of poor (often fatal) company performance. Sheldon indicates that it is very common for small firms to overlook lucrative segments, with the owner's narrow focus being the primary cause.

Almost all businesses face the critical choice of whether or not to expand. Often, small businesses are reticent about growth due to the lack of quality as sales grow, as well as the fear that the owner will not be able to do the necessary planning to develop a viable growth strategy (McCune, 1994).

The common belief that small business is the home of niche marketing is often more myth than reality (Collins, 1994). While the evidence support the viability of niche marketing (Collins, 1994), the reality is that the shotgun approach is all too common, even in the face of data that suggests for many businesses, only about $15 \%$ of the customer base is truly profitable (Hales, 1995). Mankarian (1994) postulates that the key to growing your business is proper targeting of new client bases, modifying your product line to meet the needs of these new customers.

While most attention is focused on expansion, there is a need to consider the decision to eliminate existing customer segments and/or geographic reach. As was just discussed, many choices of likely markets are inappropriate. This may be immediately apparent or emerge as an eventuality due to changing conditions. Given this, a different scenario or profile of predictive factors is quite likely.

\section{Methodology}

Sample

A written questionnaire was sent to a sample of small business owners derived from 
lists provided by the state governments of Missouri and Kansas. Only those respondents who had operated their businesses for two or more years were used in the analyses. A total of 369 usable responses $(21.07 \%$ response rate) were received; $230(62.3 \%)$ were from males and $139(37.7 \%)$ from females. The mean time of operating their business was 11.2 years.

\section{Comparison Groups}

1. Did the company subsequently add new new customer segments? Respondents were given 8 categories of customer segments and asked to classify each as (1) never having been marketed to, (2) originally marketed to but subsequently dropped, (3) emphasized less than originally, (4)emphasized the same as originally, (5) emphasized more than originally, or (6) not originally marketed to, but currently marketed to. If the respondent indicated at least one market segment was not originally marketed to but is currently marketed to, the respondent was classified in the "yes" category. $81(22.6 \%)$ were classified as yes," while $277(22.6 \%)$ were classified as "no."

2. Did the company subsequently add new geographic segments? Respondents were also given 5 categories of geographic segments and asked to respond in the same manner described above. $57(16.1 \%)$ indicated they had added or more geographic segments, and were classified as "yes," while 299 (83.9\%) did not add new geographic segments and were classified as "no."

3. Did the company subsequent drop either original customer or geographic segments? 36 respondents indicated dropping 1 or more original customer segments, while 10 indicated dropping one or more geographic segments. Since 10 cases would not allow for meaningful analysis, respondents were classified on the basis of whether they had dropped either customer or geographic segments. Forty $(11.2 \%)$ met this criterion (6 dropping both customer and geographic segments) and were classified as "yes," while 314 (88.7\%) did not drop customer or geographic segments, and were classified as "no."

\section{Dependent Variables}

A. Personal characteristics and past background

1.Gender of the respondent. Results shown as proportion of males.

2. Prior managerial/ownership experience, Respondents were asked to indicate the number of years of prior managerial/ownership experience. They were classified as "no experience" if the answer was 0 or "yes." if the answer was greater than 0 . The tables of results will show the proportion of "yes" respondents.

3. Prior marketing/sales experience. Since the primary focus of this study is on the small business owners marketing strategy, it is incumbent that marketing/sales experience prior to starting the business be considered. Respondents were asked to indicate the number of years of prior marketing/sales experience. They were classified "no experience" if they responded 0 , and "yes" if they responded greater than 0 . The tables of results show the proportion of "yes" respondents.

4.Prior experience in this industry. Knowledge of the industry in which one is trying to compete would be a critical component in achieving a viable set of marketing choices. Respondents were asked to indicate the number of years of prior experience in their industry. They were classified "no experience" if they responded 0 , and "yes" if they responded greater than 0 . The table of results show the 
proportion of "yes" respondents.

5. Age when they started the business. While there is a natural potential (not always true, however) that older individuals will be more experienced, the case can also be made that individuals of different ages will vary in terms of attitudes regarding desirable size of business, choice of products, changing products, and other issues of relevance.

6. Attained a college education. It would be interesting to note if significant differences are found between the comparison groups, i.e., is the split really one of education or of other assumed factors. Respondents were classified as "yes" if they had earned a college degree and "no" if they had not. Results shown in the tables indicate the proportion of respondents who had earned a college degree.

7. High monitoring of the business' marketing environment. Psychologists have long contended that individuals that individuals have markedly different predisposition's towards monitoring environmental cues (Snyder 1982, 1987). A growing body of business related research (c.f. Hunt and Adams, 1996) reinforces this contention. Since such monitoring behavior is an ongoing part of the individual's behavioral profile, we would expect it to be a relevant issue during all phases of the business' evolution. This variable was operationalized by asking respondents to indicate the degree to which they monitored both their customers and competitors (Adams, 1987). Factor analyses showed those as a common factor with a factor score 84. A combined score greater than the mean was classified as a "high monitor" while a score below the mean was classified as a "low monitor." Results shown in the tables indicate the proportion of respondents who were classified as high monitors.

(B) Activities and decisions made during the start-up phase of the business.
1. Prepared a business plan prior to starting the business. Respondents were classified as "no" or yes." In the tables of results, the proportion of "yes" respondents were indicated.

2. Did the respondent initially have partners? The decision to start a business with one or more partners reflects the desire to enhance the business' resource base. Respondents were classified as "no" or "yes" and the results shown reflect the proportion of "yes" respondents.

3. High start-up capital. Small businesses are notorious for initial undercapitalization. The median respondent in this study had an initial start-up capital of $\$ 8000$. "High" start-up capital was operationalized as any amount over $\$ 10,000$. Results shown in the tables indicate the proportion of respondents in the "high" group.

4. Initial marketing budget as \% of first year's projected sales. This reflects the owner's initial commitment to marketing; it also allows us to avoid the fallacy of associating higher absolute expenditures with higher commitment.

5. Started with innovative product line. The first major marketing choice of the business owner is whether s/he will offer an initial product line/mix that is the same as is commonly offered in the marketplace or whether it will represent a distinctive alternative. Respondents were given 4 options regarding how they would describe their initial product line: well-established, significant variation, recently developed, or totally new. Respondents who chose well-established were classified as "traditional," while respondents who chose any of the other 3 were classified as "innovative". Results shown in the tables indicate the proportion of "innovative" respondents.

6. Sought marketing assistance during the first 
year of operation. Respondents were given 6 possible choices reflecting hiring marketing/ sales specialists as employees, partaking in educational opportunities to enhance their own marketing knowledge, or utilizing free or for fee outside consultants. A yes response to any one of the 6 resulted in the respondent being classified as a "yes." Results in the tables indicate the proportion of "yes" respondents.

7. Number of initial customer segments marketed to. Respondents were given a choice of 8 possible customer segments (general public, government, industrial/business, professional users, hobbyists/recreation, ethnic identified customers, gender identified customers, and other). Respondents were asked to indicate for each of the eight segments if they never targeted this segment, no longer targeted this segment, targeted this segment less today than initially, targeted this segment the same as they did initially, targeted this segment more today than initially, or targeted this segment today but not initially. A response of no longer, far less, same or more indicated that the segment was one that the business had initially targeted. This variable was the sum of the total number of segments initially targeted .

8. Number of initial geographic segments marketed to. The identical approach was taken for geographic scope, except here there were 5 geographic segments (local, extended local, regional, national, and international) that the respondents were asked to consider.

9. First year's sales versus projections. Respondents were asked to indicate if their first year sales were $(-1)$ more than $20 \%$ below their projections, $(0)$ within $+/-20 \%$ of their projections, or $(+1)$ more than $20 \%$ higher than their projections. The results shown for this variable is the group mean, which is indicative of whether the group as a whole had more owners who fell significantly short of their projections versus significantly surpassed their projections.

(C) Subsequent changes in marketing strategy.

1. Subsequently added distinctively new products/services to their product line/mix. This was considered independently of whether or not they abandoned their original product line. Results shown in the table indicate the proportion of respondents who did add such products.

2. Subsequently dropped the original product line/mix. The extremeness of this decision makes it worthy of consideration. The results in the table indicate the proportion of respondents who did abandon their original product lines.

3. Added new customer (geographic) segments. if the respondent answered "targeted now but not originally" to one or more of the 8 customer segments or to one or more of the 5 geographic segments, s/he was classified "yes" on that particular variable. The results shown in the tables indicate the proportion of "yes" respondents.

4. Dropped customer (geographic) categories. If the respondent indicated "no longer" for one or more of the 8 customer segments or to one of the 5 geographic segments, s/he was classified as "yes" on that particular variable. The results shown in the tables indicate the proportion of "yes" respondents.

5. Number of changes in customer (geographic) segments. While adding or dropping a customer segment are the most extreme changes, increasing or decreasing emphasis of an original customer or geographic segment also reflect a shift in marketing strategy. This variable was operationalized as the number of customer (geographic) segments where the respondent indicated either "no longer," "far 
Table 1

T-Test comparisons of small business owners who add new customer segments versus those who do not add new customer segments.

Dependent variables

Did Not Add

Added

A) Personal Characteristics and Past Backgrounds

Proportion males

.61

Prior managerial/ownership experience

.67

Prior marketing/sales experience

Prior experience in this industry

Age when started business

37.0

College education

High monitors of the business marketing environment

B) Activities and decisions made during the start-up phase

Prepared a business plan prior to start-up $\quad .35$

High start-up capital

Initial marketing budget as \% of first year's sales

6.8

Started with innovative product line

Sought marketing assistance during first year of operation

Number of initial customer segments marketed to

Number of initial geographic segments marketed to

First year's sales versus projections

C) Subsequent changes in marketing strategy

Subsequently added distinctively new product line

Subsequently dropped original product line

Added new geographic segments

Dropped customer/geographic segments

Number of changes in customer segments

Number of changes in geographic segments

Overall customer expansion

Overall geographic expansion

Percentage of current workforce with marketing/sales as primary duty

${ }^{*} \mathrm{p}<.05$ or better 
originally."

6. Overall customer (geographic) expansion. This is the net result of "targeted now but not originally," + "more" - "far less" - "no longer." This variable measures the overall expansion or contraction of the business' marketing thrusts regarding customer (geographic) segments.

7. Non-government expansion of customer segments. Overall customer expansion of the other 7 customer segments. This is applicable when dealing with stratum that are characterized by marketing to government. Since respondents were not asked to indicate what level of government they dealt with, there is no assumed relationship with geographic segmentation.

8. Percentage of current workforce with marketing/sales as primary duty.

\section{Results}

A. Comparison of those who added new customer segments versus those who did not. Eighty one respondents indicated that they subsequently added new customer segments, while 278 respondents indicated that they did not. T-test comparisons between the two groups are shown in Table 1.

The only personal variable that was significantly different between these two groups was monitoring behavior, respondents who added new customer segment were significantly more likely to be high monitors (.71 versus $.55, \mathrm{p}<.01$ ). Closely related were two other differences: (1) they were also more likely to have sought marketing assistance during the first year of operating their business $(.75$ versus $.53, p<.05)$ and $(2)$ they were more likely to have subsequently abandoned their original product line or mix (.23 versus $.09, \mathrm{p}<.001$ ). This suggests that a large number had to pursue new customer segments due to their decision to reorient their product strategy. Of the respondents who dropped their original product line, twenty seven also added new customer segments, versus thirteen who kept their starting customer segments.

The strongest difference between the two groups was that those who added new customer segments had initially marketed to, on average, about one less customer segment ( 2.87 versus $3.83, \mathrm{p}<.0001$ ). However, their decision to add new customer segments was not merely a "stand alone" decision. Those who added new customer segments were also far more likely to add new geographic segments $(.41$ versus $.09, p<.0001)$, make more overall changes in the emphasis they gave to various geographic segments (2.98 vs, 1.54 , $\mathrm{p}<.0001$ ), markedly expanded their customer base through both new customers and higher activity directed towards original customers ( 2.35 vs. .57, $\mathrm{p}<.0001)$, and engaged in higher levels of geographic expansion (1.13 versus $.76, \mathrm{p}<.05$ ), even though their original geographic base was almost identical to those who did not add new customer segments. These results suggest that while adding new customer segments is often associated with expanding a reduced initial customer base, it also is commonly associated with either making major changes to the company's product line or as a part of a broader expansion strategy covering both customers and geographic scope.

B. Comparing those respondents who changed the geographic scope of their marketing efforts with those who did not. Fifty seven respondents indicated that they subsequently marketed to new geographic segments, while 299 indicated that they did not. The results of $t$ test comparisons between these two groups are shown in Table 2. 
Table 2

T-Test comparisons of small business owners who add new geographic segments versus those who do not add new geographic segments

Dependent variables

A) Personal Characteristics and Past Backgrounds

Proportion males

Prior managerial/ownership experience

Prior marketing/sales experience

Prior experience in this industry

Age when started business

College education

High monitors of the business marketing environment

B) Activities and decisions made during the start-up phase

Prepared a business plan prior to start-up

High start-up capital

Initial marketing budget as \% of first year's sales

Started with innovative product line

Sought marketing assistance during first year of operation

Number of initial customer segments marketed to

Number of initial geographic segments marketed to

First year's sales versus projections

C) Subsequent changes in marketing strategy

Subsequently added distinctively new product line

Subsequently dropped original product line

Added new customer segments

Added new geographic segments

Number of changes in customer segments

Number of changes in geographic segments

Overall customer expansion

Overall geographic expansion

Percentage of current workforce with marketing/sales as primary duty

.63

.66

.57

.73

36.9

.65

.54

Did Not Add

Added

.61

.55

.72

.61

$* \mathrm{p}<.05$ or better 
These results suggest a parallel phenomenon to what was found with those respondents who added new customer segments. In both cases, those who added were significantly more likely to be high monitors ( 80 versus .54 for those who did not add geographic segments, $\mathrm{p}<.001$ ), were more likely to have sought marketing assistance during their first year of operation (.82 versus .54 for those who did not add geographic segments, $\mathrm{p}<.05$ ), and more likely to have subsequently dropped their original product line $(.22$ versus . $10, \mathrm{p}<.001$ ). Just as those who added customer segments were significantly lower in the number of starting segments marketed to, so to were those adding geographic segments (2.07 versus $2.85, \mathrm{p}<.0001)$. Again, the level of subsequent expansion far exceeded a mere catch-up (2.45 versus .53 for those who did not add new geographic segments, $\mathrm{p}<.001$ ).

As was the case with those who added new customer segments, those who added new geographic segments were far more likely to be simultaneously adding new customer segments $(.56$ versus $.15, p<.0001)$. A review of the respondents showed that 251 added neither customer nor geographic segments, 71 added one or the other, and 32 added both. Given this, it was decided to perform a comparison of these three groups, with the key question being whether differences tended to (1) be more pronounced and (2) linear, i.e. those changing both were significantly higher/ lower on key dimensions that those who only changed one.

C. Comparison of those respondents who did not add new customer or geographic segments versus those who only added one versus those who added both.

Analysis of Variance, with Tukey's T pairwise comparisons, were performed between these three groups; the results are shown in Table 3. A review of these results suggests that there is a markedly different profile that emerges for those who only added one versus those who added both. Respondents whose companies only added either new customer or new geographic segments were significantly lower that both of the other groups in terms of having had prior experience in their industry $(p<.05$ for both pairwise comparisons). They attained significantly higher initial success (at least compared with their projections for first year's sales) with almost $30 \%$ more of them exceeding their projections by at least $20 \%$ than was the case for the other two groups. Finally, they were far more likely to subsequently add distinctively new product lines than either of the other groups ( $p<.001$ for both pairwise comparisons). These results suggest a scenario where many of these respondents were initially tentative (due to a lack of prior industry experience), attained initial success, expanded their product mix and their scope of who or where they marketed to. In contrast, those respondents who decided to add both new customer and geographic segments followed the same trends seen in Tables 1 and 2.

D. Characteristics of those who dropped either customer or geographic segments. Just as small business owners have the option to expand the scope of their marketing, so too do they have the possibility of deciding to drop one or more customer or geographic segments. Forty of the respondents indicated that they had dropped either customer (36) or geographic (10) segments (6 had dropped both types).

Comparing the two groups, it was found that there were no significant differences in terms of personal variables; this contrasts with the consistent finding that respondents who expanded were significantly more likely to be high monitors. However, we 
Table 3

ANOVA (With Tukey's T) Comparisons of small business owners who (1) did not add customer or geographic segments, (2) added one or the other, and (3) added both customer and geographic segments.

Dependent variables

A) Personal Characteristics and Past Backgrounds

Prior managerial/ownership experience

Prior marketing/sales experience

Prior experience in this industry

Age when started business

College education

High monitors of the business marketing environment

B) Activities and decisions made during the start-up phase

Prepared a business plan prior to start-up

Initially had partners

High start-up capital

Initial marketing budget as \% of first year's sales

Started with innovative product line

Sought marketing assistance during first year of operation

Number of initial customer segments marketed to

Number of initial geographic segments marketed to

First year's sales versus projections

C) Subsequent changes in marketing strategy

Subsequently added distinctively new product line

Subsequently dropped original product line

Dropped customer segments

Dropped geographic segments

Number of changes in customer segments

Number of changes in geographic segments

Overall customer expansion

Overall geographic expansion

Percentage of current workforce with marketing/sales as primary duty

\begin{tabular}{|c|c|c|c|}
\hline $\begin{array}{l}\text { Did not } \\
\text { add }\end{array}$ & $\begin{array}{l}\text { Added } \\
\text { one }\end{array}$ & $\begin{array}{l}\text { Added } \\
\text { both }\end{array}$ & F Score \\
\hline .67 & .62 & .63 & .40 \\
\hline .57 & .55 & .56 & .03 \\
\hline $.75 \mathrm{~B}^{*}$ & .61 & $.80 \mathrm{~B}^{*}$ & $3.41^{*}$ \\
\hline 37.1 & 35.9 & 38.6 & .92 \\
\hline .66 & .63 & .56 & .61 \\
\hline .53 & $.71 \mathrm{~A}^{*}$ & $.81 \mathrm{~A}^{*}$ & $7.81 *$ \\
\hline .34 & .29 & .43 & .98 \\
\hline .37 & .34 & .21 & 1.43 \\
\hline .39 & .40 & .33 & .25 \\
\hline 6.9 & 7.8 & 5.8 & .17 \\
\hline .22 & .19 & .35 & 1.63 \\
\hline .51 & $.76 \mathrm{~A}^{*}$ & $.81 \mathrm{~A}^{*}$ & $4.03 *$ \\
\hline $3.80 \mathrm{~B}^{*} \mathrm{C} *$ & 3.30 & 2.93 & 3.91 \\
\hline 2.82 & 2.76 & $1.96 \mathrm{~A}^{*} \mathrm{~B}^{*}$ & $5.99 *$ \\
\hline-.02 & $.24 \mathrm{~A}^{*} \mathrm{C}^{*}$ & -.04 & $3.91 *$ \\
\hline .33 & $.55 \mathrm{~A}^{*} \mathrm{C}^{*}$ & .35 & $6.93 *$ \\
\hline .08 & $.21 \mathrm{~A}^{*}$ & $.25 \mathrm{~A}^{*}$ & $7.40^{*}$ \\
\hline .09 & .14 & .09 & .47 \\
\hline .02 & .02 & .03 & .04 \\
\hline 1.49 & $2.59 \mathrm{~A} *$ & $3.28 \mathrm{~A}^{*}$ & $25.8 *$ \\
\hline 1.10 & $1.73 A^{*}$ & $2.43 \mathrm{~A}^{*} \mathrm{~B}^{*}$ & $16.4 *$ \\
\hline .57 & $1.64 *$ & $2.68 \mathrm{~A}^{*} \mathrm{~B}^{*}$ & $35.3 *$ \\
\hline .56 & $1.22 \mathrm{~A} *$ & $2.21 A^{*} B^{*}$ & $25.5^{*}$ \\
\hline 23.6 & 24.8 & 23.9 & .04 \\
\hline
\end{tabular}

$*_{p}<.05$ or better; $A=$ Significantly higher than low experience/low monitor group; $B=$ Significantly higher than low experience/high monitor group; and $\mathrm{C}=$ Significantly higher than high 
Table 4

T-Test comparisons of small business owners who dropped customer and/or geographic segments with those who did not.

Dependent variables

Did not drop

Dropped

A) Personal Characteristics and Past Backgrounds

Proportion males

Prior managerial/ownership experience

Prior marketing/sales experience

Prior experience in this industry

Age when started business

College education

High monitors of the business marketing environment

B) Activities and decisions made during the start-up phase

Prepared a business plan prior to start-up

High start-up capital

Initial marketing budget as \% of first year's sales

Stärted with innovative product line

Sought marketing assistance during first year of operation

Number of initial customer segments marketed to

Number of initial geographic segments marketed to

First year's sales versus projections

C) Subsequent changes in marketing strategy

Subsequently added distinctively new product line

Subsequently dropped original product line

Added new customer segments

Added new geographic segments

Number of changes in customer segments.

Number of changes in geographic segments

Overall customer expansion

Overall geographic expansion

Dropped either customer/geographic segments duty

${ }^{*} \mathrm{p}<.05$ or better 
again found that those who dropped customers or reduced geographic scope were significantly more likely to seek outside marketing assistance during the start-up phase of their business $(.90$ versus $.54, \mathrm{p}<.001)$. The key findings of these comparisons were those that dropped customer or geographic segments started with significantly more initial customer segments marketed to (4.70 versus 3.48 , $\mathrm{P}<.001)$. While these latter results were not significantly higher than the proportions found for respondents who did not drop customer or geographic segments, they were higher. This suggests that those who dropped customers were both initially and subsequently aggressive in their pursuit of the broadest base of customers. While these data do not support this for geographic scope.

\section{Discussion}

Data gathered from a sample of 369 Midwestern small business owners suggests that the decisions to over time add new customer segments, expand geographic scope of marketing, and drop original customer and geographic were fairly common (approximately $22 \%, 15 \%$, and $10 \%$ respectively). These data suggest that those business owners who expand are frequently those who start from the smallest bases (a logically intuitive expectation). Interestingly, those business owners who uitimately decide to trim some of their original customers or geographic scope started aggressively and are somewhat more aggressive than the rest of the respondents in terms of subsequently expanding, which suggests that at least some of them either made poor specific choices per se or they outstripped their capacity to adequately market to often widely diverse customers.

It is interesting to note that these subsequent decisions appear to have been for the most part approached in a rational manner. The significantly higher proportion of respon- dents who were high monitors of their relevant marketing environments and who were likely to turn to outside marketing experts for assistance (if we assume that their early behavior continues to hold) support this contention.

It was interesting to note that approximately $1 / 4$ of the respondents who added customer and/or geographic segments have, at some point, dropped their original product line. Flip-flopping our perspective, we found that $42 \%$ of the respondents who dropped their original product line added new customer segments versus $19 \%$ of those respondents who did not $(\mathrm{p}<.001)$; similarly, $30 \%$ of those respondents who dropped their original product line added new geographic segments versus only $14 \%$ of those who retained their original product line $(p<.01)$. These results suggest that the conventional wisdom that initial success drives expansion may not be as true as we often assume. Rather, what may be a more common scenario is one of trial and error, with major success or failure fueling the fires of expansion. One of the more worthwhile set of findings was how respondents who only expanded customers or geographic scope (but not both) had a markedly different profile from those who expanded both their customers and geographic scope.

This research suggests that those advising the small business owner should be aware of the initial scope of the business' marketing effort (controlling for company resource base), especially as it compares to that which is typical within the industry, i.e. different industries are going to have different typical mixes of customers and geographic scope, making any "one size fits all" rule of thumb invalid. If the initial marketing thrust is below or above the norm, it is likely that unless the business owner finds a workable niching strategy, there will be an almost inevitable set of forces pushing the owner towards the mean of his/her industry. While advances 
and changes continuously occur which will change this norm, a norm will exist, with those most deviant in terms of their response for their resource base being in greatest danger. To advise a restaurant that their product is of sufficiently high quality to justify the decision to expand to new locations may prove to be sound advice. To advise them to build their first restaurant outside of Kansas City in Las Vegas (yes, a restaurant owner actually did this, but not after consulting these authors) would prove inappropriate. Understanding that (1) industries and their opportunities vary, (2) owner's starting marketing strategies vary, and (3) that owners will have different capacities for and willingness to monitor their relevant marketing environments will go a long way towards providing sounder advise to the small business client.

\section{Suggestions for Future Research}

\section{References}

1. Adams, D.C., "The Relationship Among Personality Type, Management Practices, and Sales", International Council for Small Business, $34^{\text {th }}$ Annual World Conference proceedings.

2. Berry, Sandy and Britney, Kathryn. (1996) "Market Segmentation: Key to Growth in Small Business Banking," Bank Management, 72 (1) pp. 36-38.

3. Brush, Candida. (1992) "Marketplace Information Scanning Activities of New Manufacturing Ventures," Journal of Small Business Management, 30, (4) pp. 41-51.

4. Collins, Michael. (1994) "Common Sense Niche Marketing," Small Business Reports, (9) pp. 37-45.

5. Cook, Kenneth J. (1994) AMA Complete Guide to Small Business Marketing, Lincoln Wood, Illinois; NTC Business Books, pp. 2023.

6. Hales, Michael G. "Focusing on $15 \%$ of the Pie," Bank Marketing, 27 (4), pp. 29-34.

7. Hunt, Richard E. and Adams, David. (Feb. 1996) "Start-up Critical Success Factors from the Beginning," Presented at the Small Business Institute Directors Association National Conference, San Diego, CA.

8. Mankarian, Margie. (1994) "Growing Your Consulting Business," Black Enterprise, 25 (4), pp. 108-116.

9. McCune, Jenny. (1994) "Growing Pains," Small Business Reports, 19 (10), pp. 24-35.

10. Mohan-Neill, Sumaria Indra. (1995) "The Influence of Firm's Age and Sixe on Its Environmental Scanning Activites," Journal of Small Business Management, 33 (4), pp. 1920.

11. Pelham, A.M. and Clayson, P.E. (1988) "Receptivity to Strategic Planning Tools in small Manufacturing Firms," Journal of Small Business Management, 26 (1), pp. 43-50.

12. Sheldon, Dan. (1994) "Recognizing Failure Factors Helps Small Business Turnarounds," National Productivity Review, Au- 
tumn, pp. 533-541.

Notes 